\title{
Contributos para a caraterização da retórica ambiental na imprensa generalista portuguesa
}

\author{
Rui Ramos \\ Universidade do Minho, Braga, Portugal
}

\begin{abstract}
Resumo:
Situando-se no quadro da Análise do Discurso, o presente texto descreve e analisa aspetos funcionais e configuracionais relevantes de um breve corpus de artigos jornalísticos contemporâneos que tocam a problemática ambiental. Identifica alguns dos mecanismos mais salientes sobre os quais este tipo de discurso se constrói, nomeadamente a interdiscursividade com o discurso da ciência, as suas marcas de didaticidade, o seu caráter diretivo, a dramatização criada, a modalização avaliativa do enunciador e o balanço entre argumentação e emoção sobre o qual opera. Pretende, desta forma, constituir um contributo válido para a caraterização da retórica ambiental na imprensa generalista portuguesa contemporânea, numa época em que o ambientalismo é um dos discursos mais operativos da esfera pública nacional.
\end{abstract}

\section{Palavras-chave:}

Ambientalismo, media, interdiscursividade, discurso de divulgação.

\begin{abstract}
:
Contributions to the characterisation of the environmental rhetoric in the Portuguese general press. In the framework of discourse analysis, this text describes and analyzes some of the functional and configurational aspects of a concise corpus of newspaper articles which deal with the issue of the environment. It aims to identify some of the most significant mechanisms which act as the basis for the construction of this type of discourse, namely interdiscoursivity with scientific discourse, its didacticity markers and directive nature, the dramatisation it creates, the evaluative modalisation of the enunciator and the balance between the argumentative and emotional aspects upon which it is based. In this way, the objective of this paper is to provide a valid contribution to the characterisation of environmental rhetoric in the current Portuguese general press, at a time when environmentalism is one of the most relevant discourses in the national public sphere.
\end{abstract}

Key words:

Environmentalism, media, interdiscoursivity, popularization discourse. 


\section{Introdução}

Um dos traços consistentes da construção dos textos / discursos acerca do ambiente na imprensa portuguesa contemporânea encontra-se centrado no funcionamento da interdiscursividade, em particular aquela que se verifica entre o discurso científico e o ambiental: o primeiro disponibiliza ao segundo as vozes que se fazem ouvir, as informações que se apresentam, o vocabulário que se usa e os modelos de organização textual que se adotam, assim como os elementos de autorização que credibilizam o discurso.

Por seu lado, o jornal funciona como o suporte vital do discurso de divulgação da ciência, permitindo o acesso do público não iniciado a este universo de saberes frequentemente restrito e especializado.

Desta interação resulta o texto de explicação mediática, concretizando o caráter parcialmente didático da imprensa. Aquela é historicamente concebida como vulgarização, divulgação ou, mais recentemente, como recontextualização do discurso da ciência através dos media e, em princípio, pretenderia atingir o objetivo pragmático dominante de tornar os leitores mais competentes -o que constitui o objetivo fundamental que carateriza qualquer texto considerado didático. Contudo, a análise de muitos artigos concretos da imprensa generalista portuguesa permite identificar igualmente outros objetivos fundamentais, que se apresentam implicitamente (em grande parte dos casos) ou explicitamente: os objetivos pragmáticos de fazer-acreditar e de fazer-aderir, para atingir um fim derradeiro -o de fazer-fazer.

Estes objetivos são concretizados através da palavra edificadora do real, e através da exposição e da explicação das verdades científicas; mas resultam igualmente da interseção entre a (suposta) voz fria e autorizada da ciência e perturbantes argumentos de natureza passional.

Portanto, é pertinente identificar alguns traços da retórica "verde" tal como ela se apresenta nos media, para contribuir para a caraterização de um dos discursos dominantes da esfera pública (Jung 2001), um dos mais difundidos e mais fortemente operantes na sociedade portuguesa contemporânea.

\section{Quadro teórico geral}

2.1. O discurso sobre o ambiente na imprensa generalista portuguesa contemporânea não pode ser caraterizado por uma marca única, singular e definitiva, que permita estabelecer uma distinção imediata face aos restantes discursos que se cruzam 
e digladiam no espaço público. Contudo, pode afirmar-se a existência de um conjunto de marcas que o individualizam, que o distinguem e o afastam dos outros discursos constituídos publicamente, e que resulta de uma combinação particular de caraterísticas.

Uma dessas peculiaridades imediatamente identificável, e fortemente operativa na sua caraterização, é a presença constante de um interdiscurso científico. Pode, então, afirmar-se que o discurso mediático ambiental se encontra, a diversos níveis, intersecionado pelo discurso da ciência e manifesta bem os indícios desta influência.

Os “vários níveis" mencionados são o lexical (provavelmente, o mais ostensivo), o sintático, o textual e o argumentativo.

2.2. A interação entre o discurso científico e o ambiental produz resultados nos dois flancos desta união.

Por um lado, confere poder ao discurso científico. Este tem o seu espaço de constituição e circulação específico (a sua esfera técnica) e apresenta marcas ao nível microtextual, nomeadamente um léxico e uma sintaxe preferenciais e a tendência para a monossemização ${ }^{1}$, por oposição ao registo menos técnico do cidadão comum; além de marcas ao nível macrotextual, que respeitam ao enquadramento tipológico, às estruturas sequenciais preferidas, ou aos constrangimentos estilísticas (economia e pertinência máximas, objetividade, etc.). Este discurso obedece a restrições de uma retórica específica, normalmente exigindo a iniciação do seu público a um saber particular, explicitamente ancorado na tradição, que determina canonicamente as novas produções.

Ao nível pragmático, pode afirmar-se que a transposição das fronteiras comunicativas típicas, em direção a públicos laicos, nomeadamente aos decisores políticos, oferece ao discurso científico novas possibilidades de condicionamento ou de determinação da vida social, assim como cria novos desafios para a sua organização formal.

Sublinhe-se que a ideia, um tanto ingénua, de uma ciência fria, que descreve factos brutos com desprendida objetividade analítica, tem de se confrontar, hoje, com a de uma ciência que, em particular em certas áreas, se encontra intimamente associada ao exercício da influência relativamente a assuntos de domínio geral e da vida dos cidadãos. É o caso de toda a atividade científica relacionada com as questões

1 Genthilhomme (1984) refere, mais radicalmente, o "caráter monossémico" do discurso científico e Cassany / Martí referem a terminologia da Ciência como usando "términos unívocos" (2000: 2666), por oposição ao registo menos técnico do cidadão comum. 
ambientais, onde se identifica uma luta exposta ao cidadão leigo entre várias interpretações dos dados físicos, e até sobre aspetos técnicos da constituição desses mesmos dados ${ }^{2}$. Daí ter-se vindo a apontar que, ao invés da visão mais ou menos tradicional associada à ciência pelo cidadão comum, esta está longe de ser isenta e pura nas suas opções, imaculadamente transparente, e que a comunidade científica é alheia a pressões sociais e políticas (Calsamiglia 2003). De facto, a atividade científica encontra-se entre as atividades das sociedades contemporâneas, assume um curso dinâmico, é permeável a interesses e participa nos jogos de poder.

Por outro lado, há que reconhecer que a presença do discurso da ciência no discurso mediático, isto é, a sua transição da esfera técnica para a esfera pública, confere poder a este último. Como o discurso da ciência é frequentemente concebido pelo cidadão comum como o discurso da razão, a sua presença interdiscursiva no discurso mediático associa as posições do mediador / jornalista à autoridade e credibilidade científicas, afastando-o do que seria a irracionalidade de outras posições ou formas divergentes de interpretar os estados de coisas. Assim, é potenciada a adesão do leitor aos pontos de vista adotados pelo enunciador que evoca a voz da ciência para com ela se identificar. Harré / Brockmeier / Mühlhäusler afirmam: "one of the reasons why the natural sciences serve as a powerful source of rhetorical devices is that they incorporate within their rhetoric the idea of impersonal authority" (Harré / Brockmeier / Mühlhäusler 1999: 67). A ciência permite ao discurso mediático apresentar uma retórica da evidência, autorizando asserções aparentemente inquestionáveis e conferindo força probatória intrínseca ao discurso (Delavigne 1994) - força que joga um papel fundamental para sustentar a diretividade que o discurso ambiental frequentemente assume.

Quanto à sua organização interna, os discursos de divulgação científica nos media apresentam traços recorrentes: constroem uma realidade tendencialmente simplista (no que respeita ao âmbito especificamente científico); adotam uma visão maniqueísta e marcada por contrastes, por problematizações intensas relacionadas com as aplicações ou consequências públicas / sociais dos problemas, por confrontações entre interesses conflituantes (competição aberta e agonismo); atribuem um relevo muito mais importante às conclusões visíveis, de âmbito público / social, do que às condições e passos intermédios dos processos científicos em causa; frequentemente apagam ou ignoram alguns dos intervenientes nos processos, nomeadamente

2 Não se trata somente de expor os cidadãos leigos aos dados e às lutas das comunidades científicas, mas também de os chamar a ter voz, com vista a tomar as decisões mais sensatas e sustentáveis, no interesse das populações: "collaboration between credentialed experts and ordinary citizens promises to produce a "socially robust knowledge" (Nowotny 2003) or a "public knowledge" (Rehg 2009) which has shown its worth by surviving scrutiny across diverse and demanding settings" (Goodwin / Honeycutt 2009: 20). 
o agente; usam intensamente quantificações exatas, estatísticas, percentagens, números $^{3}$ (nem sempre enquadrando e relativizando os valores, para definir o efetivo valor que eles transportam para o assunto em causa) (Ramos 2009), apresentados nas formas textuais típicas da ciência -ilustrações, esquemas, quadros, tabelas, gráficos. Desta forma, as vozes autorizadas evocadas, os dados apresentados, as ilustrações que acompanham os textos, o vocabulário empregado, a sintaxe usada, os modos de organização textual prototípicos do discurso da ciência migram para o discurso dos media, que os incorpora e reinterpreta, conferindo-lhes novos contornos e destinando-os a novos públicos. Portanto, como referem vários investigadores ${ }^{4}$, há vantagem em deixar de tratar este fenómeno como vulgarização, transposição, reformulação ou divulgação, para passar a encará-lo como um processo complexo de recontextualização $o^{5}$ do discurso da ciência.

2.3. A presença forte da ciência no discurso mediático confere a este uma didaticidade a assinalar. Sophie Moirand tem tratado esta questão com sistematicidade ${ }^{6}$. Afirma que é fácil identificar o discurso didático quando o cenário do seu funcionamento é o de uma instituição social e historicamente definida como de ensino, por exemplo. Tarefa mais complexa será a de definir a didaticidade fora destes contextos institucionais e através da identificação de outras caraterísticas. Para o fazer, considera três tipos de condições: situacional (determinada pela situação de comunicação), formal (relativa à organização material interna do texto/discurso) e funcional (ligada ao objetivo perlocutório do discurso). Assim, configurado deste ponto de vista, um discurso didático ambicionará "tornar o alocutário mais competente", ou gerar nele um "saber-fazer", e os seus recursos formais, assim com a situação que ele cria ou à qual se associa, serão orientados para a realização feliz deste objetivo pragmático dominante. Para a autora, a didaticidade dos discursos

3 Van Dijk refere a estratégia de usar profusamente as quantificações exatas nos textos mediáticos como "number games" (1988: 88). Segundo o autor, esta estratégia "forcefully suggests truthfulness by the implied exactness of precise numbers" (Van Dijk 1988: 87). Contudo, como complemento a esta constatação, há que apontar igualmente o que é designado como "number paradox" (Koetsenruijter 2008: 194): geralmente, "people do not remember numbers in news articles; using additional numbers does not help them to evaluate the news. (...) They function as arguments to stress the fact that the source is a reliable one. They say: 'I did not make this up. I did my research. It's not guess-work, it's been counted"' (Koetsenruijter 2008: 194-195).

4 Cf., por exemplo: Wolton (1997); Calsamiglia / Bonilla / Cassany / López / Martí (2000); Bush / Moffatt / Dunn (2001); Moirand (2000, 2003); Ramos / Carvalho (2008); Ramos (2009).

5 Há que distinguir "recontextualização" e "reformulação": no presente estudo, a primeira designação remete para um mecanismo discursivo global ou macrotextual, enquanto a segunda se refere a processos de dimensão local (microtextual).

6 Cf. entre outros Moirand (1992, 1997, 1999, 2000, 2003, 2007); Moirand / Ali Bouacha / Beacco / Collinot (1995). 
está necessária e fortemente imbricada na presença do outro: "la présence de l'autre, à travers certaines catégories de la personne et à travers des désignations repérées, à travers les dires relatés, évoqués, invoqués ou imaginés, nous a paru constituer un des points d'ancrage de la didacticité" (Moirand 1992: 12). Defende que a presença do alocutário se encontra marcada no discurso do locutor, mesmo nos discursos de divulgação científica destinados ao público leigo. Contudo, sobretudo nos casos de discurso produzido fora de um quadro institucional claramente identificável como didático (ditos de "didaticidade fraca") e, nomeadamente, na imprensa generalista, estes precisam de encontrar os recursos que os qualificam e autorizam junto do alocutário - precisam de ser aceites como verdadeiros, válidos, pertinentes, fundamentados. Para isso, a evocação do discurso da ciência, com o seu véu de verdade incontestável e definitiva (ou quase...), de descrição derradeira das coisas e seus estados, constitui-se com argumento retórico de grande poder. Mesmo se o alocutário não o compreende inteiramente ou se se trata dos frequentes "number games" (Van Dijk 1988: 88) dos textos jornalísticos, o relato do discurso de uma autoridade, de um estudo científico ou de um especialista oferecerá um valor probatório ao discurso do jornalista. Portanto, a utilização estratégica da voz da ciência e dos cientistas estará ao serviço do "fazer-acreditar", etapa fundamental para a concretização do objetivo de "fazer-saber".

Se é verdade que, por um lado, um discurso didático visa "fazer-saber", por outro verifica-se que, com frequência, nos discursos públicos sobre questões ambientais e marcados por didaticidade, está presente um outro objetivo pragmático, insistentemente ocultado: o de "fazer-fazer". O envolvimento do jornalista e / ou da entidade mediática na promoção de comportamentos socialmente validados ou politicamente corretos não é condenado; pelo contrário, é correntemente aceite e até valorizado. Encontra-se, então, sob a capa da didaticidade, uma dimensão diretiva incontestável. Assim, "fazer-saber" seria somente uma etapa ou um estádio, fundamental mas não terminal, na sequência de atos que se orientam para a realização do macroato ilocutório de "fazer-fazer". Este, por seu lado, depende ainda da concretização de uma outra etapa, a de "fazer-aderir", pela interiorização concreta e pela adesão dos espíritos àquilo que é afirmado pelo locutor.

Há que sublinhar igualmente que o discurso sobre questões ambientais é marcado por uma dimensão temporal específica: trata-se de um discurso projetado no futuro. Com frequência, encontra-se asserções sobre o clima, o desaparecimento de espécies, a escassez de água potável, a degradação dos solos agrícolas, etc. -e tudo isto projetado num futuro mais próximo ou mais longínquo. Todas estas projeções são hoje marcadamente negativas. Enquanto previsões, são, naturalmente, afetadas por um grau de incerteza ou de variabilidade e, portanto, de credibilidade frágil. Para serem credíveis e aceites, têm absoluta necessidade de se autorizar, 
de construir uma retórica que lhes confira força ilocutória a este nível. E um dos seus argumentos mais fortes nesta tarefa de credibilização é a presença do discurso científico, frequentemente apresentado imbuído de certezas inabaláveis, suportando os cenários e as hipóteses avançadas. Portanto, a projeção no futuro operada pelo discurso ambiental não se confunde com adivinhação, mas simula ser / tem necessidade de ser / é ciência.

Finalmente, é necessário revisitar a natureza dos argumentos. Se a ciência é a fonte fundamental da autoridade, conferindo credibilidade às asserções, mesmo aquelas que não podem ser imediatamente verificadas (porque se projetam no futuro), um outro tipo de argumento imprime no discurso a sua presença e o seu funcionamento: o argumento passional, que toca o coração, o medo mais profundo, o sentimento de injustiça, o desejo e a necessidade vital de sobreviver. A presença deste apelo às emoções não é particularmente surpreendente: Christian Plantin afirma que argumentação e emoção se envolvem de tal forma que se tornam indissociáveis, rejeitando a conceção tradicional da argumentação que vê os afetos como "les polluants majeurs du comportement discursif rationnel" e que considera que "le discours argumentatif valide est un discours stoïque, sans émotions" (Plantin 2004: 168).

De facto, pode encontrar-se entre os múltiplos discursos acerca do ambiente um leque significativo de exemplos que realizam este jogo entre razão e emoção para atingir os seus objetivos de atrair o destinatário à leitura, o envolver, o perturbar e o persuadir.

\section{O corpus e os métodos}

O corpus deste estudo é constituído por artigos de dois diários e de um semanário de grande tiragem, selecionados pelo critério de abordarem questões sobre a relação entre o homem e o ambiente. Trata-se dos diários Público e Jornal de Notícias, respetivamente um jornal de referência e um jornal popular, e do semanário Visão, em formato de revista. Estas publicações foram escolhidas por se destinarem a públicos distintos e por apresentarem textos com organizações formais e retóricas diferenciadas.

O período escolhido corresponde ao mês de março de 2009. Este é um mês simbólico, marcando o início da primavera, e nele se contam vários dias comemorativos relacionados com o meio natural, como o dia internacional da água e o da floresta. Corresponde a um período tradicionalmente ligado à natureza e os indivíduos sentem-se, genericamente, num estado de algum despertar após o fim do inverno. 
Uma atenção particular dos media em relação a esta temática, nesta altura, não surpreende.

Há que sublinhar que este estudo não desenvolve uma análise quantitativa, e que não se trata da constituição de um corpus representativo do ponto de vista estatístico. O procedimento de recolha e triagem dos textos foi o seguinte: após uma análise de conteúdo dos artigos recolhidos -todos aqueles que, durante o período definido e nas três publicações, de alguma forma, abordam as questões que relacionam o homem com o ambiente- foram selecionados os mais ilustrativos. Trata-se, assumidamente, de uma escolha subjetiva, dentro dos limites definidos. A descrição restringe-se a este subcorpus limitado, que é composto por 20 artigos do Público, 14 artigos do Jornal de Notícias e dois da revista Visão. Destes, alguns exemplos foram selecionados para ilustrar a descrição desenvolvida.

\section{As evidências}

\subsection{A voz da ciência e a didaticidade dos textos da imprensa}

A voz da ciência está presente em vários dos artigos recolhidos. Surge sob a forma de discurso direto (DD), indireto (DI), indireto livre (DIL) ou através de alusões e as fontes são, normalmente, relatórios científicos ou os próprios cientistas, perfeitamente identificados.

O exemplo (1) apresenta a voz dos "cientistas", dos "especialistas", inicialmente em DI, depois em DD. O enunciador é adequadamente identificado e o seu estatuto de especialista ("investigador da Universidade de Colorado, Estados Unidos") é tornado bem claro, o que justifica que o jornalista dê a ouvir a sua voz. O que os especialistas fazem é avisar e alertar, os verba dicendi empregados para introduzir o DI nos primeiros parágrafos do texto. Estes verbos evocam necessariamente uma situação de risco, sendo que a sua escolha pertence inteiramente ao jornalista, resultando da avaliação que este faz dos estados de coisas e manifestando a sua modalização avaliativa enquanto mediador. A sua escolha ativa o implícito segundo o qual uma ação se torna necessária, para evitar as consequências negativas configuradas por um aviso ou um alerta, e, portanto, a dimensão diretiva do discurso está presente, ainda que de modo derivado.

As quantificações exatas marcam presença, como testemunhos do discurso científico, assim como a dimensão prospetiva, decorrente de verbos como os referidos (advertir e alertar), mas também de avisar e prever: 
(1) Cientistas avisam que o nível do mar pode subir mais do que o previsto

Especialistas reúnem-se em Copenhaga para actualizar relatório do IPCC; mas em Nova Iorque cépticos do aquecimento global dizem que não há problema

O nível do mar poderá subir mais do que se previa, alertaram ontem cientistas reunidos em Copenhaga. Segundo vários especialistas, os últimos cenários do Painel Intergovernamental para as Alterações Climáticas [...]

O IPCC previa que o nível do mar poderia subir entre 18 e 59 centímetros, até 2100. Mas agora apontam-se valores maiores. "O limite superior do aumento do nível do mar até 2100 poderá ser de um metro acima da média global”, disse Konrad Steffen, investigador da Universidade de Colorado, Estados Unidos. (Público, 11/3/2009, pp. 13) ${ }^{7}$.

O exemplo (2) retoma as quantificações exatas, insiste na evocação da ciência (por metonímia, tratando-se, agora, de um "trabalho científico"), e, de seguida, apresenta a voz de um indivíduo explicitamente qualificado. Este indivíduo explica os detalhes da sua pesquisa. Este verbum dicendi, que introduz um segmento em DI, pode ser encontrado com relativa insistência, sobretudo para evocar enunciadores apresentados como especialistas ou cientistas. No final do artigo, o verbo resumir assumirá idêntica função, introduzindo um segmento em DD. De facto, ambos demonstram a dimensão didática presente nestes artigos e tornam evidente uma das funções das vozes autorizadas: estas devem explicar, mostrar, resumir, ensinar, em suma, contribuir para fazer-saber.

Há que assinalar que o emprego das quantificações precisas funciona mais como artifício retórico do que com efetiva transmissão de informação pertinente. Não será fácil para um leitor comum imaginar exatamente o que representam "10.300 hectares", se estes forem deslocados da frase inicial do artigo, "Já arderam 10.300 hectares". A partícula modal "já", indicador das contraexpectativas de normalidade do jornalista, tem neste enunciado uma importância a não subestimar, provavelmente maior do que o próprio valor numérico.

Da mesma forma, é difícil avaliar a real importância de "uma margem de erro que nunca ultrapassa os 500 hectares". O efeito produzido nestes dois enunciados aponta para a grande dimensão da zona ardida e a dimensão reduzida da margem de erro. Estas quantificações presentes nestes textos (como, note-se, aquelas que estão presentes no exemplo (1) e nos exemplos seguintes) podem ser vistas como manifestações de uma retórica do quantificável: trata-se, como foi indicado acima, de uma estratégia de

7 Neste e nos exemplos seguintes, a formatação a negrito é nossa. 
credibilização do discurso - ainda que, como também foi referido, haja o paradoxo de os indivíduos dificilmente fixarem estes números, tendendo a conservar mais a ideia global que lhes subjaz e, portanto, servindo estes exercícios de quantificação para mostrar rigor e reclamar crédito de confiança, ou seja, fazer-acreditar.

(2) Já arderam 10.300 hectares. É este o resultado de um trabalho científico que quantificou a área ardida em Portugal continental até 25 deste mês feita a partir das imagens de satélite MODIS, da NASA, por um grupo de investigadores coordenados pelo professor José Miguel Cardoso Pereira, professor do Departamento Florestal do Instituto Superior de Agronomia. [...]

José Miguel Cardoso Pereira explica que o seu número tem uma margem de erro que nunca ultrapassa os $\mathbf{5 0 0}$ hectares [...]. Os $\mathbf{1 0 . 3 0 0}$ hectares são mais de dois terços do que ardeu durante todo o ano passado. [...]

Em 2008 até final de Março arderam 2500 hectares, um quarto do que se queimou este ano [...]. "São duas situações anómalas. O ano passado foi o ano em que ardeu menos desde que há registos fiáveis e este Março foi um Março com muita área queimada", resume Cardoso Pereira. (Público, 31/3/2009, pp. 6).

O exemplo (3) permite identificar, em primeiro lugar, aquilo que já foi apontado nos exemplos anteriores - a voz dos especialistas, citada em DI- mas também a presença de dois casos de lexemas que manifestam o caráter didático presente e a recontextualização do discurso da ciência. O primeiro é "efeito de estufa", que corresponde a uma metáfora largamente difundida e que nasceu da necessidade de explicar ao público laico um fenómeno que não é diretamente apreendido pelos sentidos dos indivíduos; a segunda é a equivalência, que este artigo estabelece por correferência, entre "carbono" e a fórmula "CO2". Esta equivalência não é cientificamente rigorosa, mas torna-se aceitável num contexto de mediação na imprensa. Este emprego do discurso da ciência sugere o funcionamento do discurso indireto livre (DIL), um tipo particular de relato de discurso frequente nos artigos da imprensa.

(3) O Secretário Executivo da Convenção Quadro das Nações Unidas para as Alterações Climáticas lançou ontem um apelo para que sejam obtidos avanços no entendimento.

Yvo de Boer considera que o marco de Bona será a chave para um acordo sobre emissões de gases com efeito de estufa. [...]

Entretanto, a crise económica levou à baixa do preço do carbono entre os 27 países industrializados [...]. A credibilidade do sistema poderá ficar em causa, dizem os especialistas citados pela Reuters, se os preços da tonelada de CO2 continuarem a descer. (Jornal de Notícias, 5/3/2009, pp. 30). 
O exemplo seguinte insiste nas quantificações precisas ("46\% do país", "37\%", " $17 \%$ ", etc.), no vocabulário técnico ("seca fraca", "normal a seco") e na evocação de uma fonte autorizada ("o último boletim climatológico do Instituto de Meteorologia"), estando todos estes recursos ao serviço da construção de uma imagem de rigor e de transmissão de informação fiável e útil. Sob a organização do artigo e o seu vocabulário, pode identificar-se, provavelmente, o recurso ao DIL, pelo reconhecimento de um provável intertexto científico, reelaborado no discurso do jornalista. Todos estes traços foram já apontados nos exemplos anteriores. O que este exemplo traz de novo é a infografia (ver Imagem 1) que acompanha o texto, explicitamente anunciada, e que torna visível a didaticidade do artigo. Este tipo de recurso retoma diretamente o protótipo do discurso da ciência, com os seus esquemas acessíveis aos iniciados, mas também o protótipo do discurso de divulgação, nomeadamente o do manual escolar ou o do manual de instruções, com as suas estratégias visuais de apoio ao texto verbal, com o objetivo de tornar o saber científico e técnico compreensível pelo público leigo, mesmo por aqueles leitores que poderão ter dificuldade em aceder à representação do mundo somente através do código verbal.

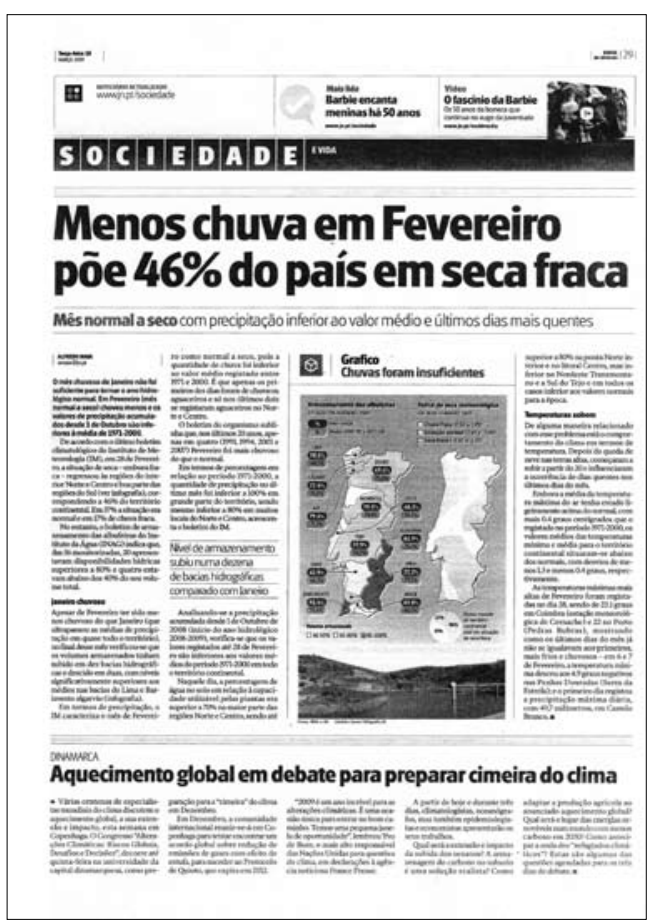

Imagem 1 - Jornal de Notícias, 10/3/2009, pp. 29

(4) Menos chuva em Fevereiro põe $\mathbf{4 6 \%}$ do país em seca fraca

Mês normal a seco com precipitação inferior ao valor médio e últimos dias mais quentes $[\ldots]$

De acordo com o último boletim climatológico do Instituto de Meteorologia (IM), em 28 de Fevereiro, a situação de seca - embora fraca - regressou às regiões do interior Norte e Centro e boa parte das regiões do Sul (ver infografia), correspondendo a $46 \%$ do território continental. (Jornal de Noticias, 10/3/2009, pp. 29). 
Finalmente (no que respeita a este tópico), o exemplo (5) atualiza algumas das caraterísticas apontadas nos casos anteriores, nomeadamente a presença de informação esquemática e visual em complemento do texto (onde se reconhecem em fundo, quase como marca de água, como se pode comprovar pela Imagem 2, um mapa-mundo, as típicas torres de arrefecimento das centrais nucleares, o símbolo da energia nuclear e outra informação gráfica), mas incorpora uma alusão a reter, uma forma difusa de relato de discurso, no seu título. Este é construído sobre um jogo de palavras que retoma a ideia de aquecimento global e cria uma nova expressão a partir desse jogo intertextual: "sobreaquecimento nuclear". Neste caso, o discurso fonte não é necessariamente o discurso da ciência (pelo menos, aquela que é a fonte direta), mas terá transitado para a linguagem comum a partir do discurso do ambientalismo.

(5) “Sobreaquecimento nuclear" (Visão, 5/3/2009, pp. 76).

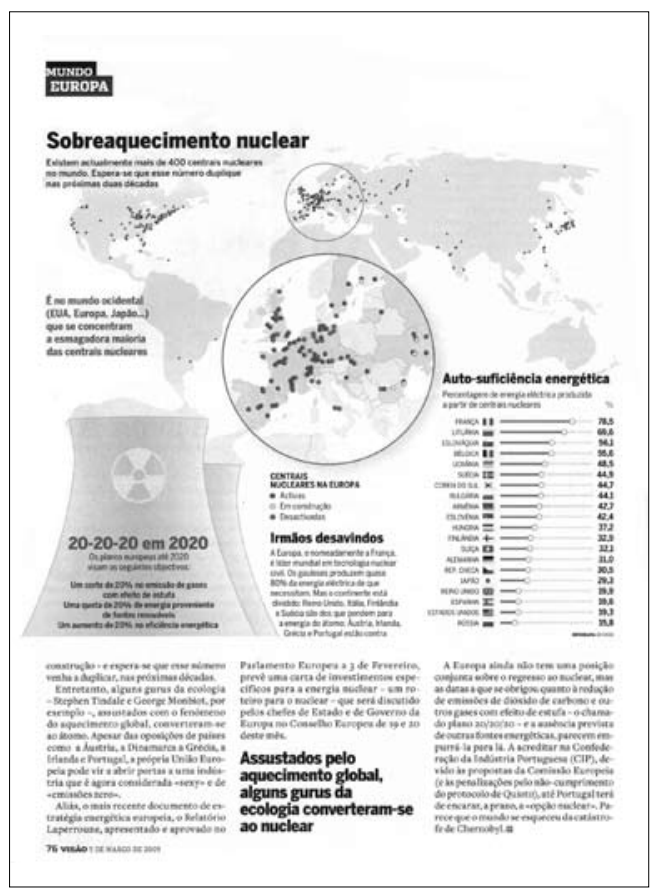

Imagem 2 - Visão, 5/3/2009, pp. 76 


\subsection{Projeções no futuro}

O exemplo (1), acima, apresentou uma evidência da projeção no futuro que carateriza muitos dos textos sobre as questões ambientais na imprensa. O exemplo (6) apresenta-nos outra, associando as projeções a um dramatismo intenso ${ }^{8}$. Neste caso, a dimensão prospetiva identifica-se no semantismo de lexemas e lexias como "destino", "até ao final do século", "ter os dias contados", "previsões", "anunciada", "anúncio", etc., ou no Futuro de várias formas verbais, como "será", "deixarão de existir", "não poderão viver aqui", "ficará submerso", etc. Esta dimensão prospetiva (e mesmo télica) marca frequentemente o discurso ambiental e, tal como alguns investigadores (nomeadamente, Harré / Brockmeier / Mühlhäusler 1999) assinalam, constrói-se sobre um conceito-chave: o da esperança. De facto, é a esperança que norteia qualquer ação em prol do ambiente: a possibilidade de alterar os estados de coisas nefastos, no sentido de garantir desenvolvimentos sustentáveis, para que as gerações futuras possam gozar de um ambiente equilibrado capaz de suportar a vida com qualidade. "Esperança" é, pois, um conceito fundamental no discurso ambientalista.

Não se confunda esta esperança com o desenho de realidades cor-de-rosa. De facto, as realidades presentes são frequentemente pintadas de cor negra, mas o tom, por mais disfórico que seja, deixa (quase) sempre uma possibilidade de salvação, de correção - o que, aliás, corresponderá ao bem comum, cuja defesa justificará o caráter impositivo dos atos diretivos que tantas vezes caraterizam a dimensão ilocutória do discurso ambiental.

No caso em análise, o texto ilustrado em (6) não é somente dramático, mas verdadeiramente pessimista, visto que não apresenta qualquer reversão possível para o problema, nenhum "happy ending", salvo uma referência breve a "quem acredite que ainda é possível evitar a subida tão radical das águas". Para além disto, focaliza-se na descrição das medidas para a adaptação dos indivíduos a uma nova e agreste realidade, dada como consumada: "planear o êxodo [para novos territórios], reforçar os corais, instalar barreiras ou construir ilhas artificiais são todos cenários de facto consumado". Trata-se de um incomum ponto de vista jornalístico (na imprensa portuguesa), que vem contrariar a tendência dos textos que, implícita ou explicitamente, adotam a postura de suportar ou promover a luta contra as alterações climáticas provocadas pela ação humana. Neste caso, a perspetiva assumida é a da adaptação. Eventualmente, poderá ser um indício da consciência pública da derrota na batalha, e uma preparação para a nova e inexorável realidade, contra a qual a

8 O caráter apocalíptico de que o ambientalismo frequentemente se reveste tem sido objeto de numerosas referências e estudos. Um dos mais recentes é o de Foust / Murphy (2009). 
ação humana é já inoperante. Trata-se da manifestação de uma retórica apocalíptica: "apocalyptic rhetoric, we argue, represents a mediating frame in global warming discourse. Certain versions of this frame may stifle individual and collective agency, due to their persistent placement of "natural" events as catastrophic, inevitable, and outside of "human" control" (Foust / Murphy 2009: 153).

A inutilidade da luta está implícita no lugar-comum sobre o qual o título do artigo se constrói, e que determina que não vale a pena lutar contra o destino. Note-se que os dois lexemas, luta e destino, estão presentes. E verifica-se um deslizamento do foco da dúvida sobre o futuro: para além de o assumir como destino, o texto volta a dar como adquirido que o roubo do país (pelas águas) é garantido, deixando a dúvida somente para o momento de tempo em que isso acontecerá. Este é um traço recorrente na retórica apocalíptica.

(6) Maldivas : um país em luta contra o destino

Se a água dos mares subir mesmo um metro até ao final do século, conforme as previsões revistas do Painel Intergovernamental para as Alterações Climáticas, da ONU, as Maldivas deixarão de existir. [...]

Para os cidadãos das Maldivas, portanto, a questão já não é se as águas lhes vão roubar o país. É quando. [...]

Como uma Atlântida moderna, a paradisíaca nação do Índico corre o risco de desaparecer sob as águas. A diferença é que a catástrofe está anunciada. Um anúncio turístico, entretanto retirado por ser considerado alarmista, dava-se mesmo ao luxo de fazer humor com a situação: "Venha visitar-nos, enquanto ainda estamos por aqui" (Público, 23/3/2009, Caderno P2, pp. 4-5).

\subsection{O caráter diretivo do ambientalismo}

O caráter diretivo (ou de fazer-fazer) do discurso ambiental pode ser identificado em grande número de textos, e é ilustrado em vários segmentos apresentados acima. No essencial, pode dizer-se que esse vetor intromissivo na liberdade individual é justificado com o superior interesse comum, e que a sobrevivência ou o equilíbrio futuro devem ser acautelados por práticas sustentáveis hoje. Esse bem comum e futuro justificarão o direito de alguns imporem a sua visão do mundo a outros, e a imposição será tão mais aceitável quanto o risco se torna intenso. A visão do mundo será sustentada com o saber científico, como acima foi referido, e a orientação argumentativa terá sempre um cariz presente-futuro. Dificilmente alguém deixará de ser sensível, pelo menos ao nível abstrato, ao argumento de preservar o futuro com pequenos gestos no presente. 
Contudo, o corpus de textos jornalísticos em análise integra uma crónica humorística publicada no diário Público, num dossier especial editado ao domingo, que põe em causa este raciocínio e estas bases argumentativas. Neste artigo, o autor afirma aceitar que os ecologistas entrem na sua casa e lhe ditem o que deve fazer para adotar um comportamento sustentável - na cozinha, no quarto, no lar em geral. E descreve, com humor, os seus pretensos comportamentos ecologicamente corretos e sustentáveis; porém, revolta-se quando lê que a Greenpeace pretende proibir a produção de papel higiénico macio, de folha tripla, porque este não pode ser fabricado a partir de papel reciclado.

Efeitos cómicos à parte, este texto testemunha um tópico central da problemática do ambientalismo: o grau de aceitação da sua dimensão diretiva pelos indivíduos. Como o humorista admite, está pronto a deixar-se convencer a abraçar um determinado número de práticas e alterações na sua vida, em prol de um futuro mais equilibrado, mas não aceita que a sua comodidade seja posta em causa para lá de um certo ponto.

Esta é uma estratégia terrorista de se opor às ideias ecologistas. Recusa a argumentação no terreno e nos termos "sérios" reclamados pelo saber científico e pela ética social e transfere-a para a esfera individual e radicalmente íntima das escolhas de índole particular, para a vida privada dos cidadãos, como se esta estivesse compartimentada e fosse alheia à sua dimensão social. Neste caso, uma eventual discussão seria praticamente impossível, porque parece não haver acordo sobre o terreno de base para que as ideias se confrontem. A argumentação ecologista dificilmente ganharia força contra o desejo inamovível de conforto na esfera íntima.

Não será por acaso que esta manifestação de resistência ocorre num formato humorístico. Num texto "sério", com argumentação racional e válida, a posição do enunciador seria indefensável. Mas um texto com este perfil pode dar a ver os caprichos, os afetos, a adesão (ou a sua falta) de cariz emocional e não puramente racional. Neste caso, apesar de a razão ditar um comportamento, a adesão dos espíritos, ou a persuasão, parece ditar outro.

O locutor parece recorrer, neste caso, a um fenómeno polifónico: põe em cena um enunciador de que claramente se distancia. O "eu" é o "homem moderno", que conhece e adere ao discurso / propostas ambientalista(s), mas esse saber e adesão não são suficientes para "fazer", pelo menos em pleno. Poderá ver-se nesta estratégia um posicionamento irónico do humorista, que desconstrói o que apresenta como uma hipocrisia da sociedade. Parece que não se atinge facilmente o último patamar do fazer-fazer. 
(7) Aceitei, com bonomia, que os ambientalistas entrassem em minha casa, trocassem as minhas lâmpadas e isolassem as minhas janelas. Deixei-os, não sem desconfiança, que penetrassem na minha cozinha. Agora só uso produtos orgânicos e cheguei a comer tofu. Não há cá nada transgénico. [...]

Já tenho é alguma dificuldade em aceitar que me invadam a privacidade na casa de banho, principalmente quando estou com as calças pelos tornozelos. Isto porque a Greenpeace pretende que se deixe de fabricar papel higiénico macio, de folha tripla, [...] porque é papel higiénico que não pode ser feito a partir de papel reciclado. [...]

Um ambientalista acusar-me-á de pôr o bem-estar do meu rabo à frente da saúde de uma árvore. Estará a ser grosseiro, mas a dizer a verdade. [...] Exijo que se cortem as árvores que forem necessárias para manter um nível de aconchego aceitável. (Publico, 29/3/2009, Caderno P2, pp. 3).

\subsection{Modalização e emoções}

Enquanto caraterística do género, o jornalista que produz uma notícia ou uma breve (genericamente, um texto de enunciação objetivizada (cf. Moirand 1999)) procura ocultar a sua subjetividade sob o relato frio e isento dos estados de coisas. Isto é o que as boas práticas determinam e é igualmente o que os próprios jornalistas tentam frequentemente fazer aceitar pelo público. Mas nenhum ser humano é isento e tomar a palavra significa instaurar um marco enunciativo, o que obriga cada ser falante a assumir-se como eu e, portanto, a perspetivar as coisas e os seus estados de uma forma singular'.

Como se viu em exemplos anteriores (nomeadamente, no exemplo (6) e, por razões diversas, no exemplo (7)), a emoção está presente. De facto, as emoções acompanham a argumentação ecologista e os jornalistas posicionam-se invariavelmente do lado das reclamações ambientais, dramatizando os problemas, ampliando riscos, agudizando perceções, potenciando as probabilidades do fazer-aderir que perseguem como etapa fundamental para o fazer-fazer final.

O texto da revista Visão de 5 de março, a propósito da opção nuclear, e que se prolonga por três páginas, com caixas de texto incorporadas, classifica a opção nuclear como uma "tentação", no seu título; na caixa de texto da página 74, apresenta

9 “Aucune prise de position épistémologique ne peut rien changer au fait que l'autonomie et donc la responsabilité du sujet, même relatives, même masquées par l'effacement énonciatif, sont inhérentes au système du langage. Elles se manifestent, entre autres, dans le rôle primordial que joue la sélection dans les procédures de mise en discours, dans la subjectivité axiologique et dans la régulation du logos et de l'ethos par «l'argumentation linguistique», mais aussi par l'»argumentation rhétorique»" (Koren 2006). Ver também Moirand (2006). 
o título "proliferação nuclear" e, como se essa expressão não ativasse já na memória interdiscursiva dos leitores todos os frames de risco e alarme, antecede-o pelo lexema "perigo", como se se tratasse de um antetítulo explicativo; e, após ter apresentado a opinião que o autor reputa mais forte no momento, favorável ao nuclear, termina da forma seguinte:

(8) Parece que o mundo se esqueceu da catástrofe de Chernobyl (Visão, $5 / 3 / 2009$, pp. 76).

A responsabilidade da classificação da opção nuclear como "tentação", a orientação interpretativa como "perigo" do título "proliferação nuclear" e a evocação de Chernobyl pertencem por completo ao jornalista e constituem uma forma de modalização. $\mathrm{O}$ primeiro caso exemplifica um traço particular de algum discurso ambiental, perpassado de alusões religiosas ${ }^{10}$-e a "tentação" dá a ver, por implicitação, a opção de alguns países como um pecado ambiental. A evocação do acidente na central nuclear de Chernobyl, explicitamente classificada como "catástrofe", torna-se pertinente como exemplo e, portanto, como alerta e como crítica: evocar aqui esse desastre, com consequências tão graves, constitui um óbvio argumento a favor da conclusão "rejeição do nuclear"; num cenário em que os argumentos se alinham com uma orientação contrária, o jornalista toma posição e vem recordar / impedir "o mundo" de se esquecer do imenso risco. Só há uma orientação argumentativa a reconhecer neste comentário final, cuja conclusão o leitor é convidado a "descobrir" por si, perante os factos: a da condenação do nuclear. E a argumentação implícita não é completamente racional, mas evoca o medo, uma das emoções mais difíceis de dominar.

De igual forma, os exemplos (9) e (10) dão a ver cenários de um dramatismo extremo para enquadrar os pontos de vista do enunciador. O título do primeiro destes artigos evoca a morte, com uma asserção criadora de um alto grau de comoção.

(9) Poluição do ar mata dois milhões em cada ano (Jornal de Notícias, 23/3/2009, pp. 29).

O texto ilustrado pelo exemplo (10), por seu lado, termina com uma outra asserção impactante, ainda mais dramática. Esta constitui exatamente a última frase do

10 Num outro contexto de discurso sobre o ambiente, Nerlich / Koteyko identificam um topos que pode ligar-se ao discurso religioso: "the compound "carbon sinner" can reference by way of metaphor either the religious frame or the diet frame, just as the interesting compound "carbon indulgence" does" (2009: 211); "the media in general tend to describe carbon emissions as "sins" and carbon credits as "indulgences" (Nerlich / Koteyko 2009: 214). Para uma análise do que designam como "green evangelicalism" nos EUA, ou seja, o discurso dos cristãos evangélicos sobre o ambiente, com a natural interseção entre o discurso religioso e o tipicamente ambiental, veja-se o trabalho de Prelli / Winters (2009). 
texto, um epílogo de grau máximo, concentrando toda a força argumentativa que o enunciador consegue imprimir ao seu discurso, na sequência de asserções e projeções graves ao longo do mesmo. Reúne, sob um único véu dantesco, a morte e as crianças, em proporções inimagináveis, e surge como argumento máximo, ao nível do logos, para sustentar a tese do enunciador, ao mesmo tempo que desempenha um papel de expoente máximo de dramatização, ao nível do pathos.

Ainda que se reclame de natureza científica, enquanto argumento a favor da utilização racional da água, esta asserção fere a consciência dos indivíduos e manifesta uma posição enunciativa clara assumida pelo jornalista: não se trata aqui da voz dos outros, é a sua própria voz que se faz ouvir para exprimir a sua subjetividade - pouco importa que os dados científicos tenham sido recebidos de um boletim ou de um relatório de outrem. Há, assumidamente, uma tentativa de influenciar a opinião pública, tornando-a favorável à ideia de partilha da água e da sua preservação, ou um fazer-fazer final, suportado por argumentos de ordem racional e passional (fazer-saber e fazer-aderir).

(10) Conflitos

Faltará água se o mundo não partilhar

A escassez de água é cenário com probabilidade agravada, se não for feito melhor uso deste recurso, lembram as Nações Unidas, que apelam à redução da poluição pelos países ricos. As alterações do clima podem trazer mais sede. $[\ldots]$

Mas não é só a disponibilidade que poderá fazer com que em 2025 cerca de 1.800 milhões de pessoas vivam em zonas com absoluta escassez e dois terços da humanidade sofram restrições no abastecimento. [...]

Em cada 15 segundos morre uma criança por doenças relacionadas com a falta de água. (Jornal de Notícias, 22/3/2009, pp. 30).

Assim, os exemplos (9) e (10) dão claramente a ver a dramatização extrema encenada pelo jornalista, aquela que envolve os sentimentos mais básicos e mais profundos, os medos e os instintos vitais: autoconservação individual, evocada na morte (primeiro caso) e mesmo a preservação da espécie, evocada no segundo exemplo, o que refere a morte de crianças a um ritmo chocante.

Acresce que, nos dois casos, o agente causador da morte é referenciado por nomes não contáveis ou vagos. No título do exemplo (9), é a "poluição do ar", ativando o frame dos problemas com o elemento ar. Em Português, "ar" é um nome não 
contável e, mesmo que se considere que é possível quantificar cientificamente os índices de poluição que ele comporta, assim como identificar cada poluente específico, de uma forma geral e para a generalidade dos indivíduos, a "poluição", no seu todo, é um conceito dificilmente materializável. O exemplo (10) identifica as "doenças relacionadas com a falta de água", o que constitui uma expressão vaga e que remete para o âmbito do uso do elemento água, apresentado igualmente como nome não contável ${ }^{11}$. Os estados de coisas evocados envolvem, então, dois elementos sem os quais a vida não é possível, mas sem identificar um responsável imediato ou palpável que seja possível apontar e, sobretudo, do qual seja possível os indivíduos protegerem-se ou contra o qual possam lutar. E lutar contra "fantasmas" ou o desconhecido amplia fortemente as dificuldades e atemoriza as expectativas.

\section{Conclusões}

De forma sintética, há que sublinhar que os exemplos apresentados testemunham topoï recorrentes do discurso acerca do ambiente na imprensa generalista portuguesa contemporânea.

Em primeiro lugar, volta a sublinhar-se a presença insistente do interdiscurso científico nos textos sobre as questões ambientais, como suporte credibilizante do discurso, identificado em DD, DI, DIL e sob formas difusas de citação, dando voz aos cientistas e citando relatórios e estudos. Fundamentadas nesta voz autorizada e autorizante, as asserções que projetam cenários futuros não se confundem com adivinhação e os conselhos, exigências e reclamações afastam-se do exercício do poder arbitrário. O leitor sabe que pode acreditar na voz do jornalista, porque esta é suportada pelas evidências científicas.

A presença da ciência testemunha uma outra dimensão do discurso ambiental na imprensa: o seu caráter didático. Não se afigura adequado afirmar que estes textos somente informam; eles também oferecem saber, explicam, tornam o leitor mais competente; enfim, ensinam.

Contudo, o leitor não se depara com a apresentação isenta ou neutra dos objetivos dados científicos. A modalização avaliativa do jornalista oculta-se frequentemente, mas também se revela em momentos-chave do discurso, e marca-o com um caráter tremendista, dramático, extremo. Estes momentos mostram que o efeito perlocutório do texto não se limita ao fazer-saber, como é próprio do típico texto didático, mas

11 Para alguns autores, como Halliday (2001) ou Chawla (2001), nas línguas ocidentais, os recursos naturais são configurados como nomes não contáveis ( a água, a energia, o ar, etc.), o que sugere o seu caráter inesgotável, não favorecendo usos racionais. 
que os dados e os recursos discursivos se orientam para fazer-crer e fazer-aderir, para ganhar a razão e a emoção do leitor. Assim, a imprensa confirma-se como poder, como instância mobilizadora, como agenciadora da vida pública, como configuradora de realidades, e a retórica "verde" encontra nela espaço de criação e ação.

\section{Referências bibliográficas}

Bush, J. / Moffatt, S. / Dunn, C. (2001): "Keeping the public informed? Public negotiation of air quality information", Public Understanding of Science 10 (2), 213-229.

Calsamiglia, H. (2003): "Popularization discourse", Discourse Studies 5 (2), 139-146.

Calsamiglia, H. / Bonilla, S. / Cassany, D. / López, C. / Martí, J. (2000): “Análisis discursivo de la divulgación científica”, em Bustos Tovar, J. J. / Charaudeau, P. / Girón Alconchel, J. L. / Iglesias Recuero, S. / López Alonso, C. (2000), Lengua, Discurso, Texto. (I Simposio Internacional de Análisis del Discurso). Vol. II, 2639-2646 (Madrid: Visor).

Cassany, D. / Martí, J. (2000): "Estrategias de divulgación de un concepto científico: el prión”, em Bustos Tovar, J. J. / Charaudeau, P. / Girón Alconchel, J. L. / Iglesias Recuero, S. / López Alonso, C. (2000), Lengua, Discurso, Texto. (I Simposio Internacional de Análisis del Discurso). Vol. II, 2665-2679 (Madrid: Visor).

Chawla, S. (2001): "Linguistic and Philosophical Roots of Our Environmental Crisis”, em Fill, A. / Mühlhäusler, P. (2001), The ecolinguistics reader. Language, ecology and environment, 115-123 (London / New York: Continuum).

Delavigne, V. (1994) : "Les discours institutionnels du nucléaire. Stratégies discursives d'euphorisation", Mots 39, 53-68.

Foust, C. R. / Murphy, W. (2009): "Revealing and Reframing Apocalyptic Tragedy in Global Warming Discourse", Environmental Communication: A Journal of Nature and Culture 3:2, 151-167.

Genthilhomme, Y. (1984): "Les faces cachées du discours scientifique”, Langue Française 64, 29-37. 
Goodwin, J. / Honeycutt, L. (2009): "When science goes public: from technical arguments to appeals to authority", Studies in Communication Sciences 9 (2), 19-30

Halliday, M. A. K. (2001): "New Ways of Meaning: The Challenge to Applied Linguistics”, em Fill, A. / Mühlhäusler, P. (2001), The ecolinguistics reader. Language, ecology and environment, 175-202 (London / New York: Continuum).

Harré, R. / Brockmeier, J. / Mühlhäusler, P. (1999): Greenspeak. A Study of Environmental Discourse (Thousand Oaks / London / New Delhi: Sage).

Jung, M. (2001): "Ecological Criticism of Language”, em Fill, A. / Mühlhäusler, P. (2001), The ecolinguistics reader. Language, ecology and environment, 270285 (London / New York: Continuum).

Koetsenruijter, W. (2008): "How numbers make news reliable", em Dam, L. I Holmgreen, L.-L. / Strunck, J. (2008), Rhetorical aspects of discourses in present-day society, 193-205 (Newcastle upon Tyne: Cambridge Scholars Publishing)

Koren, R. (2006): “Responsabilité des Uns dans le regard des Autres: l'effacement énonciatif au prisme de la prise de position argumentative", Semen 22 (Énonciation et responsabilité dans les médias [En ligne], mis en ligne le 2 mai 2007). Disponível em: http://semen.revues.org/document2820.html [Consult. em 3 de abril de 2010].

Moirand, S. (1992): “Autour de la notion de didacticité”, em CEDISCOR (org.): Les carnets du CEDISCOR, 1 (Un lieu d'inscription de la didacticité. Les catastrophes naturelles dans la presse quotidienne), 9-20 (Paris: Presses de la Sorbonne Nouvelle).

Moirand, S. (1997): "Formes discursives de la diffusion des savoirs dans les médias”, HERMÈS. Cognition, Communication, Politique 21, 33-44.

Moirand, S. (1999): "Les indices dialogiques de contextualisation dans la presse ordinaire", Cahiers de praxématique 33, 145-184.

Moirand, S. (2000): "Les manifestations discursives dialogiques de la rencontre entre sciences, médias et politique", em Bustos Tovar, J. J. / Charaudeau, P. / Girón Alconchel, J. L. / Iglesias Recuero, S. / López Alonso, C. (2000), Lengua, Discurso, Texto. (I Simposio Internacional de Análisis del Discurso). Vol. II, 2681-2697 (Madrid: Visor). 
Moirand, S. (2003): "Communicative and cognitive dimensions of discourse on science in the French media", Discourse Studies 5 (2), 175-206.

Moirand, S. (2006): “ Responsabilité et énonciation dans la presse quotidienne : questionnements sur les observables et les catégories d'analyse ", Semen 22 (Énonciation et responsabilité dans les médias, [En ligne], mis en ligne le 16 mai 2007). Disponível em: http://semen.revues.org/document2798.html [Consult. em 3 de abril de 2010].

Moirand, S. (2007): Les discours de la presse quotidienne. Observer, analyser, comprendre (Paris: PUF).

Moirand, S. / Ali Bouacha, A. / Beacco, J.-C. / Collinot, A. (eds.) (1995): Parcours linguistiques de discours spécialisés (Berne / Berlin / Francfort-s. Main / New York / Paris / Vienne: Peter Lang).

Nerlich, B. / Koteyko, N. (2009): "Carbon Reduction Activism in the UK: Lexical Creativity and Lexical Framing in the Context of Climate Change", Environmental Communication: A Journal of Nature and Culture 3:2, 206-223.

Plantin, Cr. (2004): “Ad passiones. Affects et logique dans l'argumentation”, em Marques, M. A. / Pereira, M. E. / Ramos, R. / Ermida, I. (2004), Práticas de Investigação em Análise Linguística do Discurso. Actas do II Encontro Internacional de Análise Linguística do Discurso, 163-179 (Braga: Centro de Estudos Humanísticos - Universidade do Minho).

Prelli, L. J. / Winters, T. S. (2009): "Rhetorical features of green evangelicalism", Environmental Communication: A Journal of Nature and Culture 3:2, 224243.

Ramos, R. / Carvalho, A. (2008). "Science as Rhetoric in Media Discourses on Climate Change", em Dam, L. / Holmgreen, L.-L. / Strunck, J. (2008), Rhetorical aspects of discourses in present-day society, 223-247 (Newcastle upon Tyne: Cambridge Scholars Publishing).

Ramos, R. (2009): O discurso do ambiente na imprensa e na escola. Uma abordagem linguística (Lisboa: Fundação Calouste Gulbenkian / Fundação para a Ciência e a Tecnologia).

Van Dijk, T. (1988). News as discourse (Hillsdale, New Jersey: Laurence Erlbaum).

Wolton, D. (1997): “De la vulgarisation à la communication”, HERMÈS. Cognition, Communication, Politique 21, 9-14. 